\title{
Perfectionism and the Place of the Interior Life in Business: Toward an Ethics of Personal Growth
}

\author{
Joshua S. Nunziato \\ University of Colorado, Boulder
}

\section{Ronald Paul Hill}

American University

\begin{abstract}
Stanley Cavell's moral perfectionism places the task of cultivating richer self-understanding and self-expression at the center of corporate life. We show how his approach reframes business as an opportunity for moral soul-craft, achieved through the articulation of increasingly reflective inner life in organizational culture. Instead of norming constraints on business activity, perfectionism opens new possibilities for conducting commercial exchange as a form of conversation, leading to personal growth. This approach guides executives in designing businesses that foster genius and channel creativity, while giving all stakeholders a meaningful voice within a culture of trust. We first give an account of Cavellian perfectionism. Then, we explain how this underrepresented strand of moral reflection challenges and enriches, but does not supplant, prevailing ethical theories-including other versions of perfectionism. We then demonstrate the salience of Cavellian perfectionism to business ethics through examples from marketing, human resources, and executive organizational design and development.
\end{abstract}

KEY WORDS: culture, development, exchange, inner life, values, Stanley Cavell

I never change, I simply become more myself. Joyce Carol Oates, Solstice ${ }^{1}$

M any people are seeking greater latitude for creativity, ingenuity, self-expression, and even spirituality at work today. But business ethics currently lacks a thick account of what role such dimensions of life should have in business. Our offering here is a first step toward giving such an account, and it follows the advice of Hsieh $(2017,293)$ who advocates a movement back to fundamentals that includes returning to "basic principles of ordinary morality ... for specifying the responsibilities of business managers." He goes on to describe this perspective as to do no harm, a laudable dictate that may have its basis in avoiding what may be wrong versus striving for what is good. This self-described "minimalist" approach should be widely acceptable and avoid controversies associated with more "specialized" ethical theories. Yet, the best paths forward for business ethics scholarship should 
also include "alternative theoretical paradigms" that can be more "radical" and "upend conventional theoretical wisdom" (Arnold 2016, x).

In what follows, we present a novel ethical perspective described as Cavellian perfectionism. It offers a new vantage point on forming business cultures and setting organizational strategies that invite the articulation of inner life through commercial exchanges. The article has four main parts. In the first, we introduce Cavellian perfectionism and explain why it focuses on the expression of inner life through exchange. In the second, we juxtapose Cavell's thinking with other approaches to perfectionism - and other theories of the moral life. In the third, we explore why Cavell's vision of ethical development matters for organizational culture. In the final section, we consider how Cavellian perfectionism would reorient management thinking and practice, especially in marketing, human resources, and executive organizational design and development.

\section{CAVELLIAN PERFECTIONISM: AN INTRODUCTION}

We take our lead from the Harvard philosopher Stanley Cavell (1990), who takes his orientation from multiple sources - especially Emerson, Thoreau, Wittgenstein, and Heidegger (Cavell 1990, 2; 2004, 12-3). ${ }^{2}$ All of these thinkers grapple with the question of how personal convictions should express themselves collectively as culture - an underrepresented dimension of normative reflection generally, and business ethics specifically. Tellingly, the thinkers that most influenced Cavell are not those typically cited as canonical exponents of perfectionism: e.g., Aristotle, Aquinas, Spinoza, Hegel, Marx, and Nietzsche (Bradford 2017, 344; Hurka 1993, 3). In contrast with Cavell's approach, neo-Aristotelian perfectionism is a theory that accentuates the importance of rationality, character, and habit in achieving the consummate development of human nature, which this theory treats as the goal of ethical life. One version of neo-Aristotelian perfectionism is virtue ethics, a normative theory that has been widely discussed in the business ethics literature (Audi 2012; Jackson 2012; Koehn 1998; McCracken and Shaw 1995; Moore 2005a, 2005b, 2008; Solomon 1992, 1993, 2003; Weaver 2006).

However, such discussions focus on something external: namely, excellent human practice in business. What is inside of agents matters morally only to the extent that it shapes their proclivity to act well outwardly by expressing some particular dimension of their character. (Virtue ethicists see the shaping of inner life as the social formation of the potential for human excellence through habitual action and reflection.) On the other hand, Cavellian perfectionism is an ethics of interiority. We define it as a domain of moral reflection that cultivates an increasingly articulate and circumspect manifestation of one's inner life through exchange with others who are correlatively engaged in the same process of self-transformation. ${ }^{3}$ Inner life here is more than the reflective potential for specific kinds of action, revealing particular dimensions of who one is. It is what gets cultivated through actions geared toward seeking a good that has not been codified into discrete modes of excellence (i.e., virtues). Thus, all of the insights that follow are guided by one idea: business is an opportunity for moral soulcraft, achieved through the articulation of inner life in organizational culture. 
Although Cavellian perfectionism eschews a priori criteria for moral action, it embraces the responsibility of personal cultivation and places that task at the center of the moral life. ${ }^{4}$ Cultures can be —and often are—generated accidentally. This is true both inside and outside of business. And what cultures say about those who represent them is often given scant attention. Perfectionism as we understand it cultivates people and organizations by attending intensely to what they say about themselves through what they do-and then acknowledging what is said with a fidelity that invites further growth. In the final section of this article, we draw attention to specific organizational forms that this discipline of cultivation might take.

Cavellian perfectionism courts a specific style of moral imagination. Our approach resonates, then, in certain respects, with the work on moral imagination by Werhane $(1998,1999,2002,2006)$ in that it also bridges the (apparent) gap between extant theories in business ethics and their lived expression, attuning the imagination to new possibilities. However, for Cavell, imagination is not a moral good in and of itself. Instead, its value is to enable acknowledgment of one's standing in relationship to others-and theirs in relationship to oneself. In the second section of this article, we provide a literature review contrasting Cavellian perfectionism to other versions of perfectionism, which tend to be more aligned with a business ethics of personal virtue and organizational flourishing. In that section, we also situate Cavellian perfectionism vis-a-vis prevailing normative theories. But, before getting there, it is important to have a clearer grasp of what Cavell means by perfectionism.

His perfectionism begins with the self and focuses on radical insight. It is about seeing ourselves as we truly are, not as we sometimes wish or imagine or hope or dread that we might be (Thoreau 2006) — and adjusting our work and our relationships accordingly. Thus, Cavell remarks:

Any theory must, I suppose, regard the moral creature as one that demands and recognizes the intelligibility of others to himself or herself, and of himself or herself to others; so moral conduct can be said to be based on reason, and philosophers will sometimes gloss this as the idea that moral conduct is subject to questions whose answers take the form of giving reasons. Moral Perfectionism's contribution to thinking about the moral necessity of making oneself intelligible (one's actions, one's sufferings, one's position) is, I think it can be said, its emphasis before all on becoming intelligible to oneself (Cavell 1990, xxxi). ${ }^{5}$

At first glance, the priority of self-knowledge here can seem narcissistic. Indeed, it may raise the question about whether this approach offers an ethics at all—or whether it is simply an antinomian apologia for the unbridled life of the mind. ${ }^{6}$ However, such appearances are deceptive. Cavellian Perfectionism is not an individualistic ethics - either in its orientation or its ultimate goals. Rather, the self-understanding offered by this ethics is too multidimensional- too implicated, from the beginning, in the lives of other selves and their efforts at self-expression-to lend support to intellectual navel gazing. This is why Cavell defines perfectionism as "something like a dimension or tradition of the moral life that spans the course of Western thought and concerns what used to be called the state of one's soul, a dimension that places tremendous burdens on personal relationships and on the possibility or necessity 
of the transforming of oneself and of one's society" $(1990,2)$. When people dare to speak of the soul at all today, they typically mean a zone of ineffable privacy, inaccessible to society, business, or politics. But, when Cavell speaks of the state of one's soul, he means something that brings humans into society and requires them to take responsibility for the specific shape of the larger community in which they find themselves (2004). Organizational cultivation in business expresses a particular kind of society for which, and to which, the inner life of the human being is responsible. And that specific society can help make our lives-personally and collectively-more articulate. ${ }^{7}$

What Cavell means when he insists that perfectionism begins with the self and its efforts at understanding and expression is that perfectionism teaches us to know ourselves in and through a deeper appreciation of the ways we become intelligible through one another. Thus, in a crucial passage for understanding his ethics, Cavell remarks: "What we forgot, when we deified reason, was not that reason is incompatible with feeling, but that knowledge requires acknowledgment" (Cavell $2015,319)$. Understanding who we are is not simply a matter of knowing ourselves. It is a matter of acknowledging who we are in relationship to those who teach us to know ourselves. For Cavell, we only begin to reveal ourselves as we truly are when we recognize the ways in which our lives speak for and with each other. We stand for one another. We represent each other: "To speak for oneself politically is to speak for the others with whom you consent to association, and it is to consent to be spoken for by them-not as a parent speaks for you, i.e., instead of you, but as someone in mutuality speaks for you, i.e., speaks your mind" (Cavell 1999, 27). And by "speak[ing]...politically," Cavell means something much more expansive than what we normally mean by 'talking politics.' For him, speaking politically is not just an instance of speaking one's mind. It is inseparable from expressing oneself, since we find our very selves - from the beginning-always in conversation with others. Politics, in this broader sense, is about more than the shape of the nationstate or its ends. Rather, it is simply about negotiating our place in our society. So, the promise of communal speech which articulates the inner life of each self who belongs to a given organization - a society writ small - is central to perfectionism. Thus, Cavell adds:

We do not know in advance what the content of our mutual acceptance is, how far we may be in agreement. I do not know in advance how deep my agreement with myself is, how far responsibility for the language may run. But if I am to have my own voice in it, I must be speaking for others and allow others to speak for me. The alternative to speaking for myself representatively (for someone else's consent) is not: speaking for myself privately. The alternative is having nothing to say, being voiceless, not even mute (Cavell 1999, 28).

The very condition for being able to articulate one's inner life intelligently and intelligibly is exchange with others. Cavell often calls this conversation. ${ }^{8}$ But, especially in the context of business ethics, it is helpful to remember that conversation is more than just oral or written word-transmission. The term exchange reminds us that buying, selling, working, creating, and managing can all be conversational: actions that 
open and maintain a conversation with others about who we are and what we care about. Such exchange borrows and lends the means that it uses freely and socially. When acknowledged, the conversations of business exchange lead to far-reaching ethical responsibilities. But the scope and content of these responsibilities may not be established in advance of the actual venture of exchange, which aims to deepen our mutual intelligibility and power of expression.

It is no accident that privacy and Wittgenstein's puzzles about private language haunt the background of the long quote from Cavell just cited. Cavell reads Wittgenstein as affording the insight (which can be acknowledged or refused) that the articulation of our intelligibility is irreducibly social because it happens through language and because language is irreducibly social (see 1999, part 4). Thus, Cavell comments: "In Emerson, as in Wittgenstein's Investigations, I encounter the social in my every utterance and in each silence" $(2004,4)$. When this insight gets denied it leads to skepticism. We turn in on ourselves in solipsistic narcissism. Skepticism is an ethical—not just an epistemological—posture. When the collective ownership of my means of expression (and everyone else's) gets acknowledged, that recognition allows us to express and see ourselves through the voices and the insights of others. (And conversely.)

When we speak another's mind, we reveal the inner life of that person. And that life can never be responsibly assimilated to one's own. Therefore, the ways in which we speak for one another will always be fraught with irreducible mystery. To acknowledge this mystery, Cavell sometimes has recourse to the language of the soul: "Take the phrase 'have a soul' as a mythological way of saying that I am spirit. If the body individuates flesh and spirit, singles me out, what does the soul do? It binds me to others" $(1999,411)$. When we voice our inner lives on behalf of one another, we give expression to something that links us together. But this very linkage also establishes a distance. I can only speak another's mind if I acknowledge that I cannot arrogate her inner life to mine. So, paradoxically, our souls have a social obligation to bear witness to each other's solitude. (Call this the responsibility of making another's inner life more intelligible.) We come to know and express our inner selves through others_-and not otherwise. As Cavell observes: "Being human is aspiring to being human. Since it is not aspiring to being the only human, it is an aspiration on behalf of others as well. Then we might say that being human is aspiring to being seen as human" $(1999,399)$. All the ethical impetus of Cavellian perfectionism stems from this observation. We come to know ourselves only by acknowledging others. To become fully human requires that we confer the recognition of humanity upon others - even as we seek it for ourselves. Conversely, failing to recognize other humans as sharing one's aspiration for recognition as human is - itself — a betrayal of our humanity. So shaping business cultures to afford recognition is not a distraction from perfectionism's task of knowing and expressing the self. It is the heart of that task.

To summarize: perfectionism is focused on the social self-expression of the interior life. Interiority is that dimension of human experience some philosophers have called "the state of one's soul" (Cavell 1990, 2). In distinction from other facets of experience, the interior life is manifested by one who has it and recognized 
(or ignored or denied or overlooked) by those to whom it is expressed. Interior life always invites conversation. Sometimes it requires it. The body-in its biological and social forms (e.g., corporations) - is the organ for communicating inner life. The interior life communicated through the body includes (but is not exhausted by) one's desires, hopes, dreams, affects, thoughts, illusions, convictions, expectations, prayers, intentions, prejudices, wishes, hesitations, allegiances, aversions, loves, and values. The interior life links humans together while also leaving each of them alone: committed to communicating something socially that is never simply available to others — or to oneself — as a fact for observation. ${ }^{9}$

Cavellian perfectionism-like the approaches taken to moral imagination more generally by other scholars (see Caldwell and Moberg 2007; Moberg and Seabright 2000) — complements ethical frameworks like deontology or consequentialism but does not present a competing alternative. The moral imagination instilled by perfectionism is not a conceptual framework that aspires to justify particular decisions while ruling out others on the basis of a priori criteria $(2004,2)$. Instead, it is a hermeneutical discipline. It gives us richer ways of interpreting-from the messy middle of human life-the criteria for evaluating what we say through what we do (Cavell 1999, 34). And that insight offers grounded yet sophisticated guidance to contemporary business people who are seeking new ways of forming organizational cultures that give better voice to the inner lives of those who comprise them.

\section{VARIETIES OF PERFECTIONISM AND OTHER APPROACHES TO THE MORAL LIFE}

Others have explored constructs labeled perfectionism, but often with very different descriptions and purposes. In the section that follows, we briefly contrast Cavellian ethics with four contemporary versions of perfectionism, then situate his thinking relative to other major ethical theories. For theoretical ethicists, the term perfectionism typically fits most comfortably within the ambit of a eudaimonistic virtue ethics: a style of moral reasoning focused on forming persons for living the good life, instead of on action and desirable outcomes (consequentialism) or duty and right will (deontology). Aristotle is typically credited with originating virtue ethics (Aristotle 2014). Thomas Aquinas revived it during the thirteenth century as part of the western rediscovery of the Aristotelian corpus (Aquinas 1947). And it has benefited from a resurgent interest in contemporary scholarship (e.g., MacIntyre 2007; Foot 2010; Bloomfield 2014).

The most careful and comprehensive study of perfectionism in recent decades defends a neo-Aristotelian version of the theory, which echoes central tenets of virtue ethics (Hurka 1993). According to Hurka, all versions of perfectionism "share the foundational idea that what is good, ultimately, is the development of human nature" (1993, 3; cf. Kraut 2007, Den Uyl and Rasmussen 2016). Though this is a controversial claim, it highlights two key ideas that perfectionism often (if not always) shares with virtue ethics: first, humans have a nature; and, second, this nature is one we have a responsibility to nurture. Beyond this, Hurka's distinctive perfectionism also follows Aristotle into specifics, where he finds rationality at the center of human nature. 
Even where Hurka diverges most markedly from virtue ethics (finding Aristotle's account of virtue indefensibly moralistic [1993, 19-20]), he recovers moral responsibility through an "agent-neutral" obligation to maximize the opportunities for every member of the human community to act as reflectively as possible: "Our ultimate moral goal ... is the greatest development of human nature by all humans everywhere" (1993, 55; cf., 62-3). Arguably, this perspective simply radicalizes the traditional Aristotelian virtue of justice (conditioned by magnanimity and the courage to let go of any inclination to privilege one's own development over others'), and then identifies these as the source of ethical responsibility toward one's neighbors. Since for Aristotle, justice implicitly contains all the other virtues insofar as they guide our conduct toward others $(2014,1129)$, the effect of Hurka's proposal (if not its rationale) remains close to Aristotelian virtue ethics.

Overall, the ideal of seeking to perfect human nature through the development of rationality lends a conceptual focus and clarity to Hurka's framework that most approaches to virtue ethics tend to eschew in favor of close attention to the contingencies of place, habit, and specific moral communities. Nevertheless, given its pervasive indebtedness to Aristotle, Hurka's account comports with virtue ethics on many of the points that matter most. By way of contrast, Cavell will draw on Emerson and others to give a markedly different perfectionism: one much less at home with the imagination and idiom of virtue ethics. The point of perfectionism as Cavell sees it is not the perfection of our nature (see Norris 2017, 215). (That is the thinking of Aristotle, Aquinas, and Hurka, but not really Thoreau, Emerson, or Wittgenstein.) Nor is Cavellian perfectionism about balancing different possibilities of human attainment against one another to achieve a more holistic, well-rounded version of the self (Kauppinen 2009). Instead, it is about transcending whatever we might consider our 'nature' in the direction of increasingly articulate, self-transcendent exchange—or conversation - that always leaves our 'nature' open and undefined at both its heights and depths. Indeed, Cavell will provocatively define the human as "the unnatural animal" (2010, 547). Elsewhere, writing about Thoreau, Cavell comments: "Our nature is to be overcome.... It is through nature that nature is to be overcome" (1992, 43-4). He thereby focuses not on the optimization of some quality or characteristic of a given human nature, but rather on the increasingly lucid realization of indefinite, fragmentary human lives that are always in the process of achieving better self-expression through their exchanges.

In The Perfectionist Turn: From Metanorms to Metaethics (2016), Douglas J. Den Uyl and Douglas B. Rasmussen present a sophisticated version of perfectionism as a eudaimonistic virtue theory in tandem with a liberal politics. Den Uyl and Rasmussen frame their ethics by distinguishing between a "template of respect" (e.g., deontology and consequentialism) and a "template of responsibility" (2016, 2-10). Their neoAristotelian perfectionism is an example of the latter. They see "mak[ing] a life for oneself" as its central goal (Den Uyl and Rasmussen 2016, 7). Unlike Hurka (but like Aristotle), they emphasize the role of virtue in forming each human person-in her specific singularity - for the responsibility of practical wisdom: something they equate with flourishing (2016, 33, 38-40, 54-61). At first glance, Cavell's perfectionism seems consonant with Den Uyl and Rasmussen's ethic of responsibility. However, Cavell's 
approach does not fit neatly into either of their (supposedly) "fundamental, alternative frameworks" $(2016,2)$. According to Den Uyl and Rasmussen, if one locates "the fundamental wellspring for ethical action and judgment" in the other (including oneself regarded as other), one endorses an ethic of respect. If one finds this "wellspring" in the self, one endorses an ethic of responsibility (2016, 2-8). For Cavell, our moral responsibility for self-development is the challenge of respecting others by acknowledging their potentially unlimited capability to reveal one's true self to oneself. For Cavell, if there is any such thing as a "fundamental wellspring" of the moral life it is simply the give and take of human conversation: an exchange that precedes us and forms us by inviting us to contribute something singular ourselves.

Richard Kraut gives a third version of neo-Aristotelian perfectionism (which, for mostly rhetorical reasons, he prefers to call "developmentalism"). ${ }^{10}$ Kraut's theory (in contrast with Hurka's) is focused less on rationality and more on holistic well being as a criterion for human development. Nevertheless, like Hurka and Den Uyl and Rasmussen, Kraut acknowledges his theory's considerable conceptual indebtedness to Aristotelian eudaimonism (2007, 137-8 nt. 8). He thus represents the perfectionist dimension of a larger wave of scholarly interest in ways of achieving holistic well being. For example, Martin Seligman's landmark Flourish (2012), though primarily a contribution to the field of positive psychology, has had resonance far beyond that discipline and into organizational ethics (Bright, Winn, and Kanov 2014). It has inspired work devoted to supporting positive emotions, engagement, and relationships that lead to greater life satisfaction and achievement (Cameron 2011; Sekerka, Comer, and Godwin 2014).

As with our interpretation of Cavell's perfectionism, a business ethics of flourishing seeks to ensure that work and its environment are conducive to personal development and advancement (Vogt 2005). To this end, the workplace must take into consideration the whole individual and how that person is shaped by the organization and its actors over time (Guillen, Ferrero, and Hoffman 2015). Because human flourishing has multiple objectives, these naturally resonate with functions and goals of businesses: for example (and perhaps most importantly) increased productivity. Another possibility for synergy between personal and organizational development is a focus on growing capabilities as described by Amartya Sen, manifested as skill building that serves the dual purposes of advancing personhood through spiritual development (see Guillen, Ferrero, and Hoffman 2015; Arjoon, Turriago-Hoyos, and Thoene 2018). Yet another is to seek flourishing through firm loyalty (Mele 2001; Elegido 2013).

While important and worthy objectives, our perfectionism is wary of the risk of instrumentalizing interiority by turning it into a means of achieving extrinsic organizational goals - or even, simply, external professional goals for the employeewhich do not arise from the cultivation of the inner life for and by the members of the organization. Flourishing may follow from the pursuit of cultivation, and cultivation may reshape our expectations about the form that flourishing will take. But for a Cavellian approach_as also for other forms of perfectionism (Wall 2017; Hurka 1993) — flourishing is not the aim of the moral life. ${ }^{11}$ Sometimes, the 'perfect' development of a person or an organization looks like learning how to decline 
or die well: that is, with a grace that manifests one's true self even in the process of eclipse (Cavell 2010, 540-8). The good life is not simply its flowering, as Kraut and others have supposed. ${ }^{12}$ Cultivation, as Thoreau knew well, is not merely an occupation for springtime and summer. Fall and winter, too, have their own development and perfection (cf. Walls 2017, 492-8).

A fourth version of perfectionism is provided by Yeoman (2014), who examines a "liberal perfectionist framework" to justify a political imperative that facilitates more meaningful work for employees (also see Seglow and Yeoman 2010 for a different perspective on the same argument)..$^{13}$ According to Yeoman, this imperative has remained heretofore unacknowledged because it has seemed to arise only indirectly as a contingent desire of the labor marketplace, not directly as a human need that politics must serve in order to foster the conditions of democratic society. To that end, she frames meaningfulness as something like a workers' right, which confers a correlative duty upon the state to maintain that right. Yeoman claims that what the state has an obligation to empower is personal transformation in the workplace- - the kind of change supported by a perfectionist ethic. The goal of such an approachthe transformation of workplace cultures to make them more conducive to personal self-articulation - is congruent with that of our own. However, the ethical imperative taken to motivate that change differs from the one we offer here. Where Yeoman aims to justify political action ethically in order to change business culture from 'above,' we challenge those within business organizations to recognize a heretofore unacknowledged dimension of their responsibility toward themselves and those around them-and then to foster change accordingly from within.

Perhaps precisely because of its asymmetrical relationship to other traditions, the significance of perfectionism has been underappreciated in ethical discourse-including applied ethics. Perfectionism is a dimension of ethical thinking that challenges prevailing paradigms (e.g., Kantian, Rawlsian, consequentialist, eudaimonistic)—but not by seeking to supplant them. Perfectionism offers something different: guidance for the moral formation of people and organizations. It does not give a priori criteria for resolving moral quandaries correctly. ${ }^{14}$ Nor does it justify the goodness of particular actions by deploying an a posteriori evaluative rubric. It affords relief from the relentless privilege often accorded to judgment in ethics.

As presently framed, many ethical theories-including those most influential within business ethics - tend to include a focus on "restraining the bad" (Cavell 1990, 18). Thus, they emphasize rules, obligations, limitations, responsibilities, criteria for judgment, and case studies of bad behavior. Perfectionism, in contrast, focuses on "releasing the good" (Cavell 1990, 18). Thus, it tends to emphasize opportunity, receptivity, creativity, inspiration, self-understanding, and case studies of transformative acknowledgment. While it is true that consequentialism shares with perfectionism a commitment to realizing what is good, consequentialism focuses on engineering the good rather than releasing it. Where consequentialism starts with a public criterion of what is good for the purpose of prescribing decisions and designing systems to maximally satisfy that standard, perfectionism makes space for discovering and expressing what is good through a conversation between people's public and private concerns. Thus, perfectionism leads to an ethical responsibility-but 
not one that provides a decision matrix. It is a prior, more basic commitment. Thus, Cavell refers to his perfectionism as "a register of the moral life that precedes, or intervenes in, the specification of moral theories which define the particular bases of moral judgments of particular acts or projects or characters as right or wrong, good or bad" $(2004,2)$. Perfectionism cultivates an ethos instead of legislating an effort.

The point at which perfectionism challenges other ethical theories is not by undermining their claims to accuracy or illumination. Instead, it questions their claims (whether tacit or explicit) to comprehensiveness. ${ }^{15}$ All the major strands of ethical theory tend to overlook the moral significance of interior life seeking greater intelligibility through social exchanges with others. Therefore, they have also failed to offer a thick account of the place of the inner life in business. Our recovery of perfectionism seeks to address this lacuna. Although it falls well beyond the scope of this article to identify all the blind spots in conventional ethical theories that stem from neglecting the ethical relevance of intelligible self-development, in what follows we give one example germane to business ethics and then consider how Cavellian perfectionism approaches that example differently than four different mainstream ethical theories would.

A manager thinking in consequentialist terms about the management decision of when to initiate a new product line might judge that this action would be ill-advised presently because of the pain it could cause other human beings (say, personnel within a division of the company whose weekly work hours would be doubled from 45 to 90 by the new initiative) - relative to other courses of action that would be nearly as effective, while causing significantly less distress (say, waiting six months to hire enough new personnel to launch the new product without significantly increasing the burden on existing employees). However, a manager cultivating a perfectionist mindset would also be likely to consider dimensions of the situation overlooked by consequentialists. ${ }^{16}$ For example, what does the specific suffering (and its mitigation) communicate about the particular people who are suffering? And how do those possibilities condition the sufferer's relationship to the decision maker and the community they share, with its specific norms, values, and character? Is the suffering implicit in this project likely to result in the self-development of people involved - and will it be recognized by them as such—irrespective of the success of the product launch? Or is the value of the project wholly predicated on the prospect of a successful outcome-with the suffering of those who achieve it simply to be 'offset' by the expected extrinsic gains for themselves or others in the end? In some cases, a more painful course of action —one that increases suffering for those who would execute it without offsetting gains elsewhere-might not be the unethical one. In other cases, it might be. Much depends for the perfectionist manager on how the suffering is interpreted and what it achieves for the cultivation of people involved: what the suffering means in the nexus of relationships that make up the company's culture. Thus, more is necessary for a moral timbre of life than data about pain or happiness correlated to a variable range of possible actions and predicted outcomes. The perfectionist would point out that a consequentialist analysis of this situation is useful — but incomplete. Missing is an acknowledgement of the people who suffer and the particular texture of the relationships they have with 
one another and with management. Do I treat someone as a helpless victim? Or a dispensable employee? Or a courageous colleague? Or a stubborn, but essential, member of my organization? Each of these responses will alter the moral quality of my response to the suffering involved in their work-and the potential happiness to be achieved by it. For the consequentialist, inner life is finally irrelevant for allocating quantitative goods whose maximally efficient distribution is the goal of ethics. But, for the perfectionist, any judgment about an action's economic utility must also consider its contribution to the mental, emotional, and spiritual self-understanding of those related by it.

Similar considerations would apply to a manager following a Kantian ethic. Such an executive, faced with the decision outlined above, might consider whether initiating the new product line would be consistent with the ethical goal of treating all people as ends, and not just as means (Kant 1999, 4:428-9). But a perfectionist might add that it is possible to respect one's staff while still failing to fully acknowledge what others have to teach us about ourselves. And that might be a moral failure. Cavell suggests: "Emerson's most explicit reversal of Kant lies in his picturing the intellectual hemisphere of knowledge as passive or receptive and the intuitive or instinctual hemisphere as active or spontaneous" $(1981,129)$. If even our self-knowledge is received, it might be possible to respect another person as an end without acknowledging that one is getting a clearer understanding of who one is from that person - and offering something similar in exchange. Do my decisions as a manager help my employees understand who they are more fully? Do they put me in a position to learn more about who I am as a leader from those I lead? Will the effort of initiating the new product line facilitate a deeper understanding of myself through my employees-and conversely? Such questions are instructed by a Kantian morality of respect—but they also move beyond it.

Yet again, consider the situation from the perspective of a manager who thinks like a virtue ethicist. Such a person might consider whether existing personnel would be prepared to meet the new challenge by practicing human excellence in ways that habitually instill a tendency to act well in the future when confronted with analogous situations - while also cultivating a spirit of friendship and camaraderie that promotes such habituation. More specifically, would launching the new product be likely to develop traits like courage and fortitude through collective 'resistance training' in order to build new 'moral fiber'? (Aristotle 2014) Or would it instead represent a crushing burden, more likely to cause burn-out, frustration, resignation, or even despair among employees because the situation affords no practicable way forward that allows them to develop their character through habitual effort directed toward a happy medium between vicious extremes? Likewise, the manager might consider what a prudent, just person in her position would be likely to ask of employees in a similar situation - and which decision would be most likely to cause her to grow into the capabilities of such a person (see Beabout 2012). A manager shaped by Cavellian perfectionism, on the other hand, would attend to different questions. She might ask: will this new project give my people the chance to become more reflective about their standing with others by challenging them to organize and collaborate with imagination and creativity? Will they be helping our customers to do the same? 
Or will the new demands simply force employees to entrench themselves deeper in unreflective habits of work-since there are no feasible alternatives for achieving newly-ambitious goals? For the perfectionist, what is inside matters: specifically, what is revealed about one's own interiority and that of others through (say) starting a new product line. For the virtue ethicist, inner life simply matters because it represents the potential (or character or tendency or trait) to act well by producing future actions that are better than others. But for the Cavellian perfectionist, inner life is more than a set of different potentials (or virtues) that can express a facet of the human person. Rather, inner life is the potential for expression: the condition for expressing who any of us is, in part or whole. It is the possibility of articulating oneself to others while keeping what one expresses to oneself as oneself. It is this condition - the possibility of holding a conversation, through business exchanges, as an articulate, intelligible self-that perfectionism fosters.

Finally, take the same example from a Rawlsian perspective. Imagine that the new product line is designed to address the needs of a growing, but previously underserved, marginal consumer group. A Rawlsian manager might consider whether the extra stress on staff would be fair if the new line is enabling the business to contribute to a more just distribution in society: one whose inequalities minimally disadvantage those who are least well off, in keeping with the norms that would be considered most equitable from behind the veil of ignorance (Rawls 1999, 11-3). Here, too, a perfectionist account would introduce further considerations. From a Rawlsian perspective, it is possible to achieve-and to judge oneself to have achieved - a "rational plan" for one's life that places no further ethical demands upon one's capacity for growth $(1999,370)$. But Cavell takes issue with "Rawls's claim that a rational plan of life is one that can be lived 'above reproach." Cavell comments: "It is this claim, above all I think, that my understanding of Emersonian Perfectionism contests" (1990, xxiv). Instead, Cavell suggests, remaining endlessly open to new ways of becoming a more just society—and acknowledging one's potentially unlimited implication in a somewhat unjust society-is a discipline of interiority essential for living justly (Cavell 1990, xxii-xxxviii). Thus, whatever determination the manager makes about the new product line, it ought not to support a posture of collective self-congratulation or complacency_as if the manager and her organization has done their part and can now focus on other things. The journey toward justice is exactly as open-ended as the process of growing in personal and corporate self-expression and self-understanding. Perfectionism profiles a specific path for giving voice to the human spirit. It envisions human beings as always underway to a life under constant reconsideration. Insofar as established theories offer illumination along that path, perfectionism embraces their insights. However, to the extent that such theories obstruct the self's fruitful acknowledgment of its provisionality - and the provisionality of its self-understanding-perfectionism maintains a standing challenge to reconsider one's established habits of ethical thought. And it does so by drawing attention to the claims made on and by the inner life as that life is manifested through relationships with other human beings. ${ }^{17}$ Therefore, perfectionism reserves a special place for friendship on the journey of human growth, precisely because of the inner transformation that friendship fosters. ${ }^{18}$ 
There is a difference between manifesting the good of self-development and accounting for it in terms of something else. Cavell is focused on the former, not the latter. And he sees manifestation as a function of cultivation through friendship. In this respect, he diverges from a thinker like Gwen Bradford (2017), who seeks a rational foundation for perfectionism's good (and calls this "the deep question") but remains dissatisfied with all prospective candidates.

Perfectionism is not motivated by the perplexity of a conventional moral dilemma: a situation in which multiple alternatives are presented and an agent must decide which one represents the "right" or "best" option. Instead, the problem that motivates perfectionism is the experience of being existentially dislocated (Cavell 1990, 2004). This sense of disorientation and displacement is evident in the contemporary difficulty that managers, scholars, and employees have in articulating fruitful ways for interiority to be manifested in business. Often, people do not know why business - what they spend most of their time doing — matters for the most intimate dimension of themselves. Many people rationalize this disconnection by observing that they must work to survive and that they must survive to nourish the specific kind of life they desire for themselves. But such an account avoids the question by refusing to articulate how making a living expresses the life we desire to live-or fails to do so. ${ }^{19}$ Importantly, perfectionism clarifies the place of the interior life in business. And, although this clarity is much needed, prevailing approaches to business ethics have failed to offer it.

\section{THE ORGANIZATIONAL IMPORTANCE OF INTERIORITY}

Stanley Cavell (1990) takes Ralph Waldo Emerson as a canonical exponent of perfectionism. This Emersonian ethics starts in the intimate depths of the human interior-beginning with an attitude that Emerson calls "self-reliance" (Emerson 1960, 147-49). But it ends in the ways we design our social spaces and configure our business relationships (Cavell 1990). Thoreau calls this "get[ting] our living together" (Thoreau 2006, 76). Accordingly, having supportive leaders who seek deeper self-understanding and personal transformation through their work is a key tenet of this business ethics. This support will often take the shape of education, coaching, and consulting that empowers leaders to express their highest values, their deepest aspirations, and their biggest dreams through the organizational design and culture they create. Although the specific values, aspirations, and dreams of each person are unique - and will be uniquely expressed in any given organization - the social mandate of perfectionism is to foster corporate cultures that encourage everyone in the organization to undertake their own journey of deeper self-understanding and personal transformation through their work. The unique responsibility of executives involves expressing their own values, aspirations, and dreams by offering a business ecosystem in which other stakeholders can fully manifest theirs.

For perfectionism, the biggest obstacle to "releasing the good" is not circumstances, other people, or the law. Rather, it is the self. The self gets in the way by failing to understand itself and by refusing to remain open to the possibility of its - and society's - transformation. One name for this obstruction is "despair" 
(Cavell 1990, 18). Thoreau called it "quiet desperation," and Emerson called it "melancholy" (Thoreau 2006, 7; Emerson 1960, 261). It is manifested through thoughtless conformity, ignorance, dispiritedness, and unoriginality. Perfectionism responds to such despair by providing a compelling alternative. Cavell remarks: "Emersonian Perfectionism can be taken as the paradoxical task of secularizing the question of the profit in gaining the whole world and losing one's soul" (Cavell 1990, 26; cf., 18). By challenging people to face up to this question, perfectionism responds to the calculus of despair.

The great business crises of our time have more to do than is often recognized with a failure of perfectionist aspirations toward self-development in the context of workplaces that foster too much conformity, narrow thinking, "playing it safe," and the investment of the self's purposes in predefined social roles and expectations. The problem is often not that people do not know what the right thing is. The problem is that they are in a corporate culture that makes resistance to bad decisions seem futile or irrelevant. (Many cases could be adduced, but the scandal at Wells Fargo involving 'forced' new accounts is just one recent example.)

A symptom of this underlying malaise is the temptation among some business workers to treat compliance as a sufficient criterion for ethical conduct. Such an attitude is reflected in the mentality that something's legality is an adequate proxy for its permissibility. But instead of focusing on compliance, perfectionist leaders will promote workplaces that reward a pluralistic spiritual originality by granting people safe space to distinctively understand and express their deepest concerns. They will not create organizations that privilege survival over meaning-making. Sometimes, the interior significance of our lives - individually and collectively - is more important than the fact that they continue. Perfectionist leaders will recognize this perspective and promote corporate cultures that recognize it as well..$^{20}$

Perfectionism takes the shape of a quest or journey with a clear direction but no endpoint (Cavell 2004, 3). Cavell remarks: "Emersonian Perfectionism does not imply perfectibility - nothing in Emerson is more constant than his scorn of the idea that any given state of what he calls the self is the last" (Cavell 1990, 3). The challenge of perfectionism is to be always moving from what Cavell (following Emerson) refers to as one's "attained self" to one's "unattained but attainable self" (Cavell 1990, 12). It is not as if the "attained self" is who one really is and the "unattained but attainable self" is who one might eventually become. Rather, both are aspects of the self, which is always in transition between different possible versions. Once you have attained a new, richer self (and, with it, a deeper self-understanding) you will be able to recognize yet another "unattained but attainable self."

Thus, there is no finish line to spiritual growth, but the quest itself is the process of perfection. ${ }^{21}$ Business leaders can undertake that quest by making organizations that socially express a readiness to bring into the world most clearly and fruitfully what its members have at heart to create. (Such organizations are precisely what their founders had at heart to create.) The result are companies-as well as workers-that are constantly in the process of transit from their "attained" selves to "unattained but attainable" possibilities. 
No one else can tell someone how to attain her "unattained but attainable self." (If someone else could, it would not be her self that that person was attaining. It would be someone else's ideal.) But the process of achieving "self-reliance" (Emerson 1960, 149; Cavell 1990, 36) will require tapping into what Emerson calls one's "genius": the intimate source of inspiration, verve, and creativity that we all have-but only a few convincingly express for others to see and appreciate. Cavell calls Emersonian genius "the capacity for self-reliance" (Cavell 1990, 26). If one had a stable, fixed self-understanding, self-reliance would be straightforward: it would look like bootstrapping. It would focus on the discipline of doing everything for oneself and depending on no one else for anything. Such an attitude often comes across as austere and impressive - but also cold, hard, and elitist (Cavell 1990). Such a disposition, however, is not what Emerson meant by self-reliance. His portrait of the self (and his own self-understanding) is too dynamic - transfixed by the process of evolution and growth - to allow for self-reliance to ossify into arrogant indifference or narcissistic overconfidence. Instead, self-reliance is about a willing readiness that allows some previously unexpressed goodness and creative power to come to fuller expression in and as one's self. Indeed, Andrew Norris argues: "Self-reliance, as Cavell has it, is itself the exercise not of power but of reception" $(2017,212)$. This idea is why Cavell claims: "Responsibility remains a task of responsiveness. I shall in effect be saying that the moral perfectionism I am most interested in exemplifies and studies this responsiveness" (Cavell 1990, 25). Although no one can achieve one's higher self in one's place (or tell anyone else how), people can support one another in the process of increasing self-insight and inner fruitfulness. Emerson $(1960,104)$ observes, "Truly speaking, it is not instruction, but provocation, that I can receive from another soul." ${ }^{\prime 22}$ That task of offering fruitful provocation to one another on the journey of personal growth is the touchstone of a perfectionist business ethics.

Indeed, founders, executives, and other business leaders manifest their genius by fostering organizational spaces most conducive for others to manifest their geniuses through fulfilling missions of organizations to which they belong. Perfectionist leaders create organizations that empower participants to express the offerings, gifts, talents, and insights that are uniquely theirs to bring into the world. Such leaders will not treat employees or other stakeholders simply as interchangeable capital: productive resources from which value can be extracted without attending to what each person reveals about herself in and through her work. Instead, perfectionist leaders treat other people as capable, even desirous, of offering unexpected, serendipitous, and inspired value to the firm. Perfectionism thus shares with stakeholder theory a commitment to articulating a rich account of the firm's social ecology, which is calculated to influence the way that value is produced and distributed (Freeman 1994; Agle et al. 2008; Freeman et al. 2010).

Concretely, this requires organizational designs that allow for much greater flexibility in the roles that people serve in their organizations and how they fulfill those roles. Enhanced personal flexibility will afford employees greater visibility as to the direct impact their work is having on themselves and the larger world. And it will offer them more control over and contact with the nexus of inputs, decisions, and outputs that make the goods they produce or services they offer meaningful 
and worthwhile to all. The overall goal of greater 'touch' is a more dynamic match between the needs of the organization and employees' strengths and potential.

Friendships are crucial for the perfectionist because they exemplify possibilities of human excellence that are not one's own-but that might become one's own. A friend need not be someone you like, try to get along with, or for whom you have a special affinity. Rather, a perfectionist friend is a "beautiful enemy" (Emerson 1909, 67): beautiful because she shows you some excellence that you have not seen in yourself and an enemy precisely because she reveals something that you are not (yet) (Dula 2011). Such a revelation can result in jealousy and envy. Or it can result in appreciation, admiration, and personal growth. When the latter happens, the friendship is fruitful.

In business, a perfectionist ethics suggests that we need more such friendships within organizations, across roles in organizations, and with external stakeholders (including suppliers, customers, and shareholders). But, this does not mean that people just need to "like one another more" or "learn how to play nice" or force an affinity where it is lacking. Instead, corporate cultures need spaces for organic, cross-functional, horizontal partnerships characterized by exemplary talent, trust, and reciprocal support. Leaders need to create safe spaces for treating colleagues as companions: people who cooperate in the making of a livelihood through the dynamic growth of mutual self-understanding (see Thoreau 2006).

\section{BUSINESS IMPLICATIONS OF PERFECTIONISM}

In what follows, we offer examples of differences that a perfectionist orientation can make for various business practices. (These examples are summarized in Table 1.) We present examples spanning three firm contexts: marketing, human resources, and executive organizational development and design. These are clearly not exhaustive but are meant to suggest avenues for reflection and additional study by managers.

\section{Marketing}

First, we look at marketing. When perfectionist marketers design new offerings, they do so by moving beyond simple targeting and differentiating strategies of: "What will people buy? And how can I efficiently deliver what they desire?" Instead, they consider the self-understanding of people on both sides of the exchange equation, those that make and those that buy such goods and services, recognizing their inherent tensions. For example, firms and their organizational actors often seek to extract as much as possible from consumers who seek value for money rendered (see Hill and Martin 2014). Perfectionist marketers, on the other hand, use interiority to more fully understand and articulate these tensions, seeking ways to serve interests of these parties so that all are acknowledged through the exchange. Such acknowledgment, in turn, leads to trust. And trust makes parties more receptive to insights about themselves that they have to gain and offer through their transactions. An ethical frame like social contract theory emphasizes long-term equity over short-term egoism (Watkins and Hill 2007). A perfectionist approach goes further 
Table 1: Summary of Perfectionism's Business Implications for Three Key Divisions of a Typical Company

\begin{tabular}{|c|c|c|c|}
\hline Division: & Marketing & Human Resources & Executive Team \\
\hline \multirow{4}{*}{$\begin{array}{l}\text { Relevant } \\
\quad \text { Function(s): }\end{array}$} & Product Design & \multirow{2}{*}{$\begin{array}{l}\text { Crafting an Employee } \\
\text { Value Proposition }\end{array}$} & \multirow{4}{*}{$\begin{array}{l}\text { Organizational Design } \\
\text { Culture Setting }\end{array}$} \\
\hline & Promotion & & \\
\hline & Pricing & Compensating & \\
\hline & Physical Distribution & Hiring & \\
\hline \multirow[t]{3}{*}{$\begin{array}{l}\text { Impact of a } \\
\quad \text { Perfectionist } \\
\quad \text { Ethic: }\end{array}$} & $\begin{array}{l}\text { Design in ways that help } \\
\text { people understand } \\
\text { themselves better and } \\
\text { express themselves } \\
\text { more clearly. } \\
\text { Promote thick modes } \\
\text { of human connection } \\
\text { through one's brand. }\end{array}$ & $\begin{array}{l}\text { Focus on intrinsic motivations } \\
\text { in setting the employee } \\
\text { value proposition by offering } \\
\text { a uniquely hospitable } \\
\text { ecosystem for creativity, } \\
\text { self-expression, and } \\
\text { personal and professional } \\
\text { development. }\end{array}$ & \multirow{3}{*}{$\begin{array}{l}\text { Design organizations to } \\
\text { afford all stakeholders } \\
\text { the greatest } \\
\text { opportunities for } \\
\text { growth by bringing } \\
\text { something new and } \\
\text { meaningful into the } \\
\text { world through their } \\
\text { own genius. } \\
\text { Set cultures that foster } \\
\text { exchange as mutually } \\
\text { self-enriching } \\
\text { conversation-both } \\
\text { within the organization } \\
\text { and with stakeholders } \\
\text { outside of it. }\end{array}$} \\
\hline & $\begin{array}{l}\text { Price to empower the } \\
\text { self-development of } \\
\text { internal stakeholders, } \\
\text { the corporation, and } \\
\text { customers. }\end{array}$ & $\begin{array}{l}\text { Compensate to acknowledge } \\
\text { value added-and the person } \\
\text { who added the value-not to } \\
\text { offset agents for the disutility } \\
\text { accrued by their work. }\end{array}$ & \\
\hline & $\begin{array}{l}\text { Distribute in a way } \\
\text { that fosters real } \\
\text { conversation across } \\
\text { a diverse customer } \\
\text { base. }\end{array}$ & $\begin{array}{l}\text { Hire by considering a } \\
\text { candidate's capacity for } \\
\text { self-awareness and personal } \\
\text { growth, not simply that } \\
\text { person's perceived } \\
\text { contribution to the firm's } \\
\text { human capital. }\end{array}$ & \\
\hline
\end{tabular}

by suggesting that the "conversation of justice" (Cavell, 1990)—carried on through our business exchanges - is valuable because it teaches us to recognize ourselves for who we really are through our commercial partners.

The moral imagination instilled by Cavellian perfectionism would also focus on what these marketer decisions reveal about people who make them in relationship to consumers and other stakeholders. Unlike consequentialist thinking, perfectionism would draw special attention to what outcomes of marketing actions convey symbolically about the larger nexus of human exchange relationships to which they belong. Such moral communications may manifest, or mask, intentions of managers charged with resolving complex situations by thinking outside ordinary organizational and functional constraints. They may say something about relationships both within and outside the organization. Sometimes, what they say is good. Sometimes, not so much. But attention and imagination are necessary to discern what is actually being said by such actions. Good intentions are not enough to ensure morally meaningful actions by marketers - unless they come to expression in their implementation.

Another marketing consideration involves the rise of social media that is popularized in such widely read books as Alone Together: Why We Expect More from Technology and Less from Each Other and iGen: Why Today's Super-Connected Kids Are Growing Up Less Rebellious, More Tolerant, Less Happy-and Completely Unprepared for Adulthood - and What That Means for the Rest of Us, which point out the inverse 
correlation between virtual 'connectedness' and personal well-being (Turkle 2017; Twenge 2006). Marketing managers, who are increasingly using social media and associated analytics, may choose to focus on data that registers active media users, time spent on various platforms, and other measures of product interest. However, perfectionist marketers at such companies would be more likely to absorb data about big-picture, long-term implications of how their marketing strategies and tactics positively and/or negatively impact customers' lives across a number of dimensions. For example, perfectionism would challenge marketers to consider how their particular products fit into and support the constellation of needs that determine the quality of life of consumers (Hill and Martin 2014) — but now with 'quality of life' understood in terms of the potential for deepened self-inquiry and self-expression that people have within their communities. Marketers could then identify new ways to support meaningful human connectedness through relationships with products and people across the larger marketplace.

What is the right price for a product that has been designed by a perfectionist manager? Once again, considerations that come into play will supplement and enrich the typical economic calculus and accounting ratios. A perfectionist marketing executive considers pricing strategies that can maximize availability of their products to the broader market of consumers whose lives can be positively impacted by usage (Hill and Martin 2014), while simultaneously returning value to the employees, managers, shareholders, and other stakeholders who conjointly created the product or are impacted by its development and selling. This is not a matter of attempting to hit abstract 'fair prices.' Nor it is a matter of a company seeking to maximize the total resources it extracts from its customer base. Instead, it is a question of dynamically adjusting the pricing of one's offering to ensure that all who produce it are remunerated in ways that empower them to continue expressing their inner values and personal commitments through their participation in the conversation of business exchange. On the demand side, ideal pricing strategies reflect a commitment to fostering diverse brand communities that contribute to customers' journey of self-development by helping them become more intelligible to themselves and others. Such pricing will reflect the benefit to the customer embedded in the firm's ongoing ability to grow-while simultaneously promoting more widespread access to products that encourage thicker customer conversations.

Finally, a perfectionist approach to distribution would focus on increasing access to new markets and customers - especially the overlooked and underserved. This is not corporate philanthropy operating under the guise of a beneficent market strategy. Rather, expanding the scope of distribution is desirable because it enlarges the nexus of exchanges - the potential for conversations - taking place between those within the firm and those outside of it. We often learn to know and express ourselves better through conversations with heretofore unfamiliar voices-and conversely. Thus, by bringing the members of an organization into richer, more diverse, and less predictable relationships with a larger set of customers, the firm opens new opportunities for self-expression and understanding — both inside and outside of the organization. This represents an oblique - yet powerful—avenue for businesses to achieve social impact through their core operations. For example, technology 
has expanded distribution options beyond traditional retailers and shopping malls, but its reach tends to be concentrated on affluent communities, leaving behind the most vulnerable consumers in the marketplace. Acknowledging interiority should recognize who is and who is not engaged in the marketplace, seeking to increase the diversity of people served and boosting the trust across relevant stakeholders. Firms may have to include marketing tactics that are now increasingly obsolete in a digital age that suffers from media fragmentation and lower reach per media outlet.

\section{Human Resources}

Beyond the marketing function, a perfectionist ethic would also shape human resources departments in a number of very specific ways. Consider how a perfectionist HR manager might craft the firm's employee value proposition. Generally, business managers have focused heavily on extrinsic motivation to hire and inspire employees to support their companies' missions (see Bénabou and Tirole 2003 for a discussion of motivation). However, from a perfectionist perspective, the role of intrinsic motivation has been comparatively underappreciated. Yet rethinking HR with an emphasis on the cultivation and expression of inner life will lead to a focus on novel internal motivations to guide hiring and retention efforts while giving employees a line of sight to the link between their extrinsic compensation and the inherent value of their work. It will encourage managers to stop asking: "What compensation package is required to get this person to come here?" and to begin asking "What kind of culture, development opportunities, and organizational infrastructure do we need to have in place so that the promise of personal growth is an overwhelmingly attractive consideration to our best candidates?" Here personal growth would include the opportunity to know oneself more deeply as a person through one's growing professional expertise. It would also include the chance to build trusting relationships of reciprocal instruction in the workplace, whether with coworkers, vendors, customers, clients, investors, or others.

By way of example, one specific practice for creating such a culture over time is to include a series of frank, standardized questions during the hiring process that prompt honest conversation about the actual mission of the organization and how the candidate's personal life purposes align—or do not—with that collective purpose. Ideally, such conversations would directly inform custom onboarding processes and targeted professional growth opportunities throughout each employee's tenure. Such practices prompt employees to understand their own aims and values more clearly and expansively by being given the opportunity to express them in the context of a corporate matrix, where other aims and values are concurrently coming to expression. Implementing such a practice, however, will require HR managers to focus explicitly on the role that their firm might play in the self-development of their employees-while emphasizing this dimension of the company's offering in their hiring and retention efforts. Marketing culture to attract people who will grow personally while growing the company and those around them requires much more attention than is typically given to the ways in which various roles specifically afford occasions for employees to understand and express their personal convictions, commitments, and even spirituality at work (see Weymes 2005). 
This is not (simply) a question of entertaining or fun workplaces with foosball tables and free food. (Though these things can sometimes foster friendship in the workplace.) It is about affording opportunities for all employees to become better versions of themselves because of their places in systems where they are valued. Even low-level jobs like cashier or line cook can provide ways for worker self-expression and deepening personal insight about one's character, values, and motivations if surrounding business environments are both inviting and inclusive and there are clear avenues for growth and advancement to more sophisticated roles. Ways in which businesses promote such an ethos include emphasizing mentorship opportunities for employees (not just those recognized as rising stars) (Eby et al. 2008), providing access to development options, and making it easy to receive education on a variety of personal and professional fronts.

Obviously, what someone gets out of working can be more than their pay and benefits (Thomas 2009) — but it also includes these perks. Perfectionist leaders believe that the primary role of compensation is offering acknowledgment for the value added to customers and other stakeholders by employees. From this perspective, compensation is a means of recognizing people by empowering them to provide for their own needs and desires just as, and because they, have helped provide for the needs and desires of others through their work. When workers feel that their compensation accurately reflects their contributions, that package harmonizes with a larger corporate context that supports employees as they articulate their inner lives on the job. Yet, when pay is perceived by employees to be inequitable, it will be viewed as a sign of disrespect and cause distrust. This message may undermine other managerial efforts to boost intrinsic employee motivation. Thus, if employees are going to be afforded work that enables them to realize their potential as human beings by providing something that helps others understand and express themselves, it is crucial that a recognition of that service be communicated to them through their compensation and other associated motivators.

A perfectionist paradigm also has implications for hiring processes. Managers always seek individuals who have ability to do the job, but perfectionist leaders similarly desire that employees have the capacity for increasingly reflective interiority. One simple way of looking for this potentiality is examining paths taken over time by potential workers. Personal and professional journeys yield insights about the priority that candidates have placed on self-reflection and inner growth at work. Another possibility is to discuss candidates' plans for development and the extent to which interiority and seeking 'unattained but attainable selves' with earlier employers are implicitly or explicitly described. Nonetheless, it is important not to use a yardstick that eliminates someone from contention simply because he or she has not previously been given opportunities for self-development. Thus, focus should be on discerning capacity—or readiness - for growth, along with the inner conviction that such growth matters, rather than requiring that specific stages of personal growth and self-insight already be achieved.

\section{Executive Organizational Development}

Finally, perfectionism would reorient organizational design and development around the goal of creating trusting and dynamic corporate cultures. A perfectionist 
manager would be inclined to recognize that people best express their interior lives when they create spaces and occasions for others to best express theirs. Founders and executives can guide the internal architecture and ethos of their companies by designing organizations that forge links connecting internal and external stakeholders. Managers can empower employees to express what they have in their hearts in their work. The result should be novel offerings that enable mindful purchasing, deepen self-understanding, and increase chances for participating in a more engaged way in the ongoing development of firms. Such efforts will mean reconsidering the kinds of strategic goals that organizations set for themselves and the metrics used to evaluate their achievement. (For three possible directions that such a reframing might take see Savitz 2013; Roche et al. 2017; Harrison and Wicks 2013.)

The most effective business leaders are mindful of the communities that they are creating, both inside and outside the company. They foster networks of employees, customers, and investors that amplify people's authentic voices through their interactions for/with the company. Overall, then, a perfectionist manager's role in an organization is seeing others as they are and enabling others to express their inner life through working (employees), purchasing (consumers), and investing (owners). Therefore, management becomes a contemplative exercise. It is a question of attending to true needs and desires of other people and then creating an organization that meets those needs and desires in ways that elicit mindful attention and personal growth through the conversation of exchange. Individuals who are managed and served warrant the chance to become higher versions of themselves. The place of the interior life in business, therefore, is one that makes space for others to bring their convictions, values, and dreams into the world in a way that clarifies one's own. Management moves from a focus on power to a concentration on empowering; sometimes, this will correspond to a shift from hierarchical structures to inclusive and flat organizational designs that allow for wider, more flexible self-expression by participants. All stakeholders should be acknowledged-and should recognize that they have been acknowledged-by their firms. Thus, perfectionism cultivates trust and transparency.

\section{CONCLUSION}

Our view is that perfectionism is a way to encourage personal development within an organizational context that complements other ethical frames rather than acting as a substitute for them. Theoretically, perfectionism raises the question of the comprehensiveness of ethical frames such as consequentialism, deontology, virtue ethics, and Rawlsian distributive justice. Practically, we are asking business leaders to establish corporate cultures that facilitate rather than impede self-understanding and transformation through personal efforts in a collective setting. The ongoing process of self-discovery should support the continuous development of the organization-and vice versa. From this vantage point, the journey of personal growth allows for corporate renewal, not mindless conformity; and it places responsibility for such correlative development on employees, managers, and directors. It also requires allocation of the necessary time and provision of safe spaces for 
employees to consider and to express their deepest fears and most important values. In the end, company culture must be one of trust across organizational layers rather than perpetual concern that the venture will ultimately result in failure.

Of course, perfectionism is not an end state but a journey that moves the attained self to unattained but possible selves on a continuous basis across a dynamic field, consistent with the opening words of Joyce Carol Oates. Perfectionist leadership does not view employees in narrow functional or capital terms but supports their development and what that development can yield for the firm. It also requires greater managerial understanding of employee abilities and needs as they evolve over time and space, making both the how and why of corporate life subject to continuous renewal. As the firm hierarchy becomes increasingly flat, perfectionist friends are better able to support and challenge each other to seek their highest levels of understanding and seek the unattained but attainable collective organizational self.

\section{ACKNOWLEDGEMENTS}

We dedicate this article to the memory of Stanley Cavell (1926-2018), who passed away shortly before this article went to press. We are grateful to Peter Dula (Eastern Mennonite University), Kelly Martin (Colorado State University), and Kirsten Martin (George Washington University) for reading and responding to an early draft of this article. The two anonymous referees for the journal offered substantive feedback that decidedly improved the final product: we appreciate their time and close attention. The editor also deserves our thanks for important insights across several revisions.

\section{NOTES}

1. Joyce Carol Oates, Solstice (New York: Dutton, 1985), 114.

2. Only three articles have been published in Business Ethics Quarterly featuring one or more of these thinkers (Walton 1993; Solomon 1999; Duska 2014). Two of these articles have involved Heidegger, and one features Wittgenstein. The other two thinkers have never been featured. (For this purpose, an article is taken to "feature" a given thinker if that thinker's name appears in the title or abstract.) This heuristic survey simply suggests that it is not only Cavell who has yet to receive serious treatment in the business ethics literature: it is also a related group of influential philosophers who are typically seen as falling outside the canon of normative ethics. One of Cavell's achievements is to demonstrate the contributions of all four to ethical theory. Via Cavell, then, the present article implicitly brings these other thinkers to bear on business ethics.

3. Cavell's perfectionism differs from other 'isms' in that it is not simply a theory about something else. Cavell enacts what he recommends in the process of recommending it. Specifically: by writing about perfectionism, Cavell is cultivating an increasingly articulate and circumspect manifestation of his own inner life through (virtual) exchange with his readers, as he invites them to enter into the same process of self-cultivation in all areas of their lives (including business).

4. Loacker and Muhr (2009) have drawn on Foucault, Butler, and Levinas to critique "moral codes" in business ethics. Their alternative to a priori criteria bears important family resemblances to the account we give here: it emphasizes the open-endedness of the ethical self and the moral centrality of responsiveness. (Indeed, Cavell himself has noted the affinity between his perfectionism and a Foucauldian "care of self" [Cavell 2010, 479] — a concept important to Loacker and Muhr.) However, there are also important differences between our approach and theirs. Loacker and Muhr's socially self-determining agent knows that some part of itself is unknowable - but does the best that it can by others anyway, knowing that even the best rules and guidelines will be inadequate to the task (2009, 272-3). In contrast, our Cavellian approach forgoes the claim to own its own blind-spots. Instead, it simply stays receptively poised-in the midst of quotidian business - to perennially new possibilities of cultivation. For Cavell, this means understanding 
one's inner life more deeply by staying attentive to the extraordinary truths about ourselves and others revealed in everyday conversation within the community through which each has the opportunity to know herself more fully.

5. Cavell does not elaborate here on why we should try to become intelligible to ourselves. However, one possible rationale is as follows: it is good to be intelligible to ourselves because, otherwise, we lack intelligence about ourselves. We do not know who we are. And, therefore, we do not know what is good for us. We are ignorant. And ignorance is doubly bad because, not only do we not know ourselves and what is good for us: we also do not know that we do not know ourselves and what is good for us. We are lost. If, at least, we knew that we were ignorant, we would (paradoxically) already have some self-knowledge. And we would discover then that we had never been entirely ignorant. Instead, we had always had some kind of self-knowledge. But perhaps we had not always been cultivating our receptivity to ever-more-lucid intelligibility. And that cultivation is the fundamental responsibility of perfectionism. Without it, we make compromises with ignorance. (For a seminal examination of the philosophical problem of ignorance, see Plato 1997.)

6. Cavell himself acknowledges these worries head-on: "From the perspective of these theories [i.e., consequentialism and deontology], Moral Perfectionism, seeming to found itself, let us say, on a concept of truth to oneself, may appear not to have arrived at the idea, or to disdain it, of other persons as counting in moral judgment with the same weight as oneself, hence to lack the concept of morality altogether" (1990, 2).

7. There is a rich literature in both business ethics and organizational studies on the importance of meaningful work and what businesses can do to promote it. (For a survey see Michaelson, Pratt, and Grant 2014.) Although there is a clear family resemblance between the aims of these approaches and goals of the present article, they are also importantly different. It is possible to feel good about one's work without ever asking why. People may find their work to be full of meaning even though they fail to achieve deeper or more expressive self-understanding through it. One could, for example, have a medical career devoted to healing — and find great meaning in that career — without giving any consideration at all to what such work reveals about oneself or one's relationships. Thus, without engaging one's intelligence in self-reflection, meaningfulness may fail to become intelligible.

8. The role of conversation is especially prominent in Cavell's work on the Hollywood comedies of remarriage (1981). In that work, following John Milton, Cavell explores the idea that marriage itself could be a "meet and happy conversation"- - but with a twist: it is a human exchange that must always be rediscovered by the partners to it $(1981,87,146)$. Most business relationships are far less intimate than a marriage. But even in business we talk of 'partners' — and, especially between co-founders-we frequently compare the relationship to that of spouses. More broadly, however, Cavell suggests the possibility that even casual business exchanges might bear the significance and value of a lasting, insightful conversation.

9. Cavell's approach to ordinary language philosophy is a constant interrogation of the interior life reflecting on its possibilities of articulation, reception, and refusal (Cavell 1999). The genealogy Cavell offers for his philosophy of interiority runs through Ludwig Wittgenstein back to Ralph Waldo Emerson and Henry David Thoreau (Cavell 1989; cf., Wittgenstein 2009; Thoreau 2006; Emerson 1960). We regard the contemplative life as the manifestation of a well-formed, self-aware, and fruitfully expressive interiority.

10. Kraut's quibble with the term perfectionism is mostly, but not entirely, a rhetorical reservation. He also takes issue with some of the features of perfectionism that make it objectionable to Rawls: the imperative to maximize specific forms of human brilliance - and, by implication, the justification it provides for instrumentalizing human beings who are incapable of maximally expressing specific kinds of brilliance (2007, 136 nt. 4; 179-80, nt. 31). Cavell's version of perfectionism is decidedly non-elitist (see nt. 14 below). His approach would suggest that Rawls and Kraut conflate cultivation with cultural accomplishment.

11. Hurka refuses to countenance any connection here on the grounds that perfectionist well-being is either an empty pleonasm (if well being is simply another name for self-development), or it is an oxymoron (conflating the subjective category 'well being' with the objective category 'perfection') (1993, 17-8, 194 n. 17).

12. Thus, Kraut claims: "The good of an artifact looks to the good of something beyond it. Not so for living things: in their case, what is good for $\mathrm{S}$ is the flourishing of $\mathrm{S}$, or what leads to it.... For human beings, no less than other living things, it is always good to flourish; and if a human being is flourishing in all ways, both physical and psychological, he is doing very well indeed" (2007, 132-3).

13. For an examination of meaningful work from the perspective of MacIntyrian virtue ethics, see Beadle and Knight (2012). This approach emphasizes the importance of developing goods like skills, abilities, 
and tempered judgment internal to specific worthwhile practices. For work that translates these ethical ideas from conditions of production to those of consumption, see Garcia-Ruiz and Rodriguez-Lluesma (2014).

14. In the literature devoted to perfectionism and politics, there is extensive discussion about whether perfectionism is intrinsically elitist, as Rawls (for instance) has claimed (Rawls 1999, 286-8; Arneson 2000; Hurka 1993; Wall 2017; Den Uyl and Rasmussen 2016). The nagging question lurking behind the suspicion is this: what is a fair price for someone to pay for the personal development of someone elseespecially in a value-pluralistic society where we may not even agree about what development is? But perhaps responding fruitfully to such a question will require criteria that are afforded only by particular, ongoing, open-ended exchanges with others - criteria that an abstract, a priori determination of what we owe each other could only prejudice. Cavell's version of perfectionism is self-consciously democratic and non-elitist, as the opening lines of his principal work on the topic make clear $(1990,1)$.

15. Canonical formulations of traditional ethical theories have often been expressed in terms that stake a claim to comprehensiveness. Thus, in the Groundwork of the Metaphysics of Morals, Kant famously contends, "It is impossible to think of anything at all in the world, or indeed even beyond it, that could be considered good without limitation except a good will" (1999, 4:393; emphasis in original). Likewise, Mill avers in Utilitarianism, "The utilitarian doctrine is, that happiness is desirable, and the only thing desirable, as an end; all other things being only desirable as means to that end" (2017, 70). Perfectionism does not deny that happiness and good will are (or can be) morally relevant. But it keeps open the question of whether either one is really the only thing that is so.

16. Certain forms of perfectionism tend to take an objectivist bent. Like consequentialists, perfectionists insist on certain human goods that are good irrespective of the regard people have for them (Finnis 2011, 90). Such a view contrasts (for instance) with a deontological emphasis on the purity of intention as the criterion for right action. However, given its focus on passages from inner to outer and back again, Cavellian perfectionism is neither objectivist nor non-objectivist. The term fails to afford much illumination here.

17. Such tendencies may be taken to suggest an intellectual affinity between perfectionism and pragmatism. However, Cavell tends to downplay the similarities. For instance, he observes: "For my taste, pragmatism misses the depth of human restiveness, or say misses the daily, insistent split in the self that being human cannot, without harm to itself (beyond moments of ecstasy) escape, and so pragmatism's encouragement for me, while essential, is limited" $(2004,5)$. Generally speaking, Cavellian perfectionism shares with pragmatism an impulse to move beyond speculative ethical argumentation (whether in a neoKantian, consequentialist, or virtue frame). However, pragmatism is focused on what gets communicated socially. It pays little attention to who is communicating and how. But attending to these latter considerations requires that we account for what is communicated as a kind of revelation or manifestation: not simply as a social datum that drives empirically-assessable action. Seeing what we communicate as a disclosure of inner life exteriorized — but never commodified - allows us to treat communication as a conversation between people who are always together and, just so, always separate, distinct—even alone—but not isolated.

18. We are grateful to Peter Dula for encouraging us to foreground the crucial role that friendship plays in the work of personal growth - along with the critical edge that perfectionism maintains by declining to present an alternative to other ethical theories.

19. Thoreau draws this problematic to the reader's attention in Walden, especially the first two chapters, which are tellingly entitled "Economy" and "Where I Lived, and What I Lived For."

20. We see this recognition in Cavell's provocative claim, "Bearing testimony and witnessing are functions of martyrdom. In Moral Perfectionism, as represented in Emerson and in Nietzsche, we are invited to a position that is structurally one of martyrdom; not, however, in view of an idea of the divine but in aspiration to an idea of the human" (1990, 55-6). Cavell's point is not that people—or businesses—have a mandate to self-abnegation. Rather, the point is that, for perfectionist leaders and the organizations they lead, the goal of survival is never absolute. There is something more important expressed through their lives than the bare fact of their lives. (Indeed, what would such lives amount to if they were simply devoted to their own mute perpetuation?) Devotion to bare survival tends to treat growth, sustainability, or some combination of the two as exhausting the significance of business. Perfectionists see things differently. When continuing to live would violate what one's life expresses, a perfectionist will forego survival in favor of the witness of her life. (Socrates provides a paradigm case for the motivation behind such a decision.) Structurally, this condition means vulnerability to the possibility of martyrdom, at both the personal and collective levels. Therefore, witnessing the truth to the point of death will always remain an inherent possibility for a person or organization convinced that its life expresses something bigger than itself. 
21. Moral perfectionism mutates into its pathological double-scrupulous self-alienation — when the self loses the ability to recognize and claim its own expression except in the form of an ideal that it cannot achieve (Burke and Fiksenbaum 2009).

22. As Cavell points out, Emerson's picture of the self yields an account of education as recollection. Though mostly out of favor today, such a theory has both ancient and contemporary proponents. Cavell mentions Plato, Wittgenstein, and Heidegger. One could add Augustine as another influential representative.

\section{REFERENCES}

Agle, Bradley R., Thomas Donaldson, R. Edward Freeman, Michael C. Jensen, Ronald K. Mitchell, and Donna J. Wood. 2008. "Dialogue: Toward Superior Stakeholder Theory.” Business Ethics Quarterly 18 (2): 153-90.

Aquinas, Thomas. 1947. Summa Theologica. Translated by the Fathers of the English Dominican Province. New York: Benzinger.

Aristotle. 2014. Nicomachean Ethics. Translated by Roger Crisp. 2nd ed. New York: Cambridge University Press.

Arjoon, Surenda, Alvaro Turriago-Hoyos, and Ulf Thoene. 2018. "Virtuousness and the Common Good as a Conceptual Framework for Harmonizing the Goals of the Individual, Organizations, and the Economy.” Journal of Business Ethics 147 (1): 143-63.

Arneson, Richard. 2000. "Perfectionism and Politics." Ethics 111 (1): 37-63.

Arnold, Denis G. 2016. "Three Models of Impactful Business Ethics Scholarship.” Business Ethics Quarterly 26 (4): ix-xii.

Audi, Robert. 2012. "Virtue Ethics as a Resource in Business." Business Ethics Quarterly 22 (2): 273-91.

Beabout, Gregory R. 2012. "Management as a Domain-Relative Practice that Requires and Develops Practical Wisdom.” Business Ethics Quarterly 22 (2): 405-32.

Beadle, Ron, and Kelvin Knight. 2012. "Virtue and Meaningful Work." Business Ethics Quarterly 22 (2): 433-50.

Bénabou, Roland, and Jean Tirole. 2003. "Intrinsic and Extrinsic Motivation." The Review of Economic Studies 70 (3): 489-520.

Bloomfield, Paul. 2014. The Virtues of Happiness: A Theory of the Good Life. Oxford, New York: Oxford University Press.

Bradford, Gwen. 2017. "Problems for Perfectionism." Utilitas 29 (3): 344-64.

Bright, David S., Bradley A. Winn, and Jason Kanov. 2014. "Reconsidering Virtue: Differences of Perspective in Virtue Ethics and the Positive Social Sciences." Journal of Business Ethics 119 (4): 445-60.

Burke, Ronald, and Lisa Fiksenbaum. 2009. "Work Motivations, Work Outcomes, and Health: Passion Versus Addiction.” Journal of Business Ethics 84: 257-63.

Caldwell, David F., and Dennis Moberg. 2007. "An Exploratory Investigation of the Effect of Ethical Culture in Activating Moral Imagination.” Journal of Business Ethics 73 (2): 193-204.

Cameron, Kim. 2011. "Responsible Leadership as Virtuous Leadership.” Journal of Business Ethics 98 (1): 25-35.

Cavell, Stanley. 1981. Pursuits of Happiness: The Hollywood Comedy of Remarriage. Cambridge, MA, London: Harvard University Press.

Cavell, Stanley. 1989. "Finding as Founding: Taking Steps in Emerson's 'Experience." In This New Yet Unapproachable America: Lectures After Emerson after Wittgenstein. Albuquerque: Living Batch Press. 
Cavell, Stanley. 1990. Conditions Handsome and Unhandsome: The Constitution of Emersonian Perfectionism: The Carus Lectures, 1988. 1st ed. Chicago: University of Chicago Press.

Cavell, Stanley. 1992. Senses of Walden: An Expanded Edition. Chicago, London: University of Chicago Press.

Cavell, Stanley. 1999. The Claim of Reason: Wittgenstein, Skepticism, Morality, and Tragedy. Oxford: Oxford University Press.

Cavell, Stanley. 2004. Cities of Words: Pedagogical Letters on a Register of the Moral Life. Cambridge, MA; London: Belknap Press.

Cavell, Stanley. 2010. Little Did I Know: Excerpts from Memory. Stanford: Stanford University Press.

Cavell, Stanley. 2015. "The Avoidance of Love" in Must We Mean What We Say? Cambridge: Cambridge University Press.

Den Uyl, Douglas J., and Douglas Rasmussen. 2016. The Perfectionist Turn: From Metanorms to Metaethics. Edinburgh: Edinburgh University Press.

Dula, Peter. 2011. Cavell, Companionship, and Christian Theology. Oxford: Oxford University Press.

Duska, Ronald F. 2014. "Why Business Ethics Needs Rhetoric: An Aristotelian Perspective." Business Ethics Quarterly 24 (1): 119-34.

Eby, Lillian T., Tammy D. Allen, Sarah C. Evans, Thomas Ng, and David DuBois. 2008. "Does Mentoring Matter? A Multidisciplinary Meta-Analysis Comparing Mentored and Non-Mentored Individuals." Journal of Vocational Behavior 72 (2): 254-67.

Elegido, Juan M. 2013. “Does It Make Sense to Be a Loyal Employee?” Journal of Business Ethics 116 (3): 495-511.

Emerson, Ralph Waldo. 1909. Ralph Waldo Emerson, His Essay on Nature, Also Essay on Friendship. Pittsfield, MA: Caxton Society.

Emerson, Ralph Waldo. 1960. Selections from Ralph Waldo Emerson. Edited by Stephen W. Whicher. Boston: Houghton Mifflin Company.

Finnis, John. 2011. Natural Law and Natural Rights. 2nd ed. Oxford, New York: Oxford University Press.

Foot, Philippa. 2010. Natural Goodness. Oxford, New York: Oxford University Press.

Freeman, R. Edward. 1994. "The Politics of Stakeholder Theory: Some Future Directions." Business Ethics Quarterly 4 (4): 409-21.

Freeman, R. Edward, Jeffrey S. Harrison, Andrew C. Wicks, Bidhan L. Parmar, and Simone de Colle. 2010. Stakeholder Theory: The State of the Art. Cambridge, New York: Cambridge University Press.

Garcia-Ruiz, Pablo, and Carlos Rodriguez-Lluesma. 2014. "Consumption Practices: A Virtue Ethics Approach.” Business Ethics Quarterly 24 (4): 509-31.

Guillen, Manuel, Ignacio Ferrero, and W. Michael Hoffman. 2015. "The Neglected Ethical and Spiritual Motivations in the Workplace." Journal of Business Ethics 128 (4): 803-16.

Harrison, Jeffrey S., and Andrew C. Wicks. 2013. "Stakeholder Theory, Value, and Firm Performance.” Business Ethics Quarterly 23 (1): 97-124.

Hill, Ronald Paul, and Kelly L. Martin. 2014. "Broadening the Paradigm of Marketing as Exchange: A Public Policy and Marketing Perspective.” Journal of Public Policy \& Marketing 33 (Spring): 17-33.

Hsieh, Nien-hê. 2017. "The Responsibilities and Role of Business in Relation to Society: Back to Basics?" Business Ethics Quarterly 27 (2): 293-314.

Hurka, Thomas. 1993. Perfectionism. New York: Oxford University Press. 
Jackson, Kevin. 2012. Virtuosity in Business: Invisible Law Guiding the Invisible Hand. Philadelphia: University of Pennsylvania Press.

Kant, Immanuel. 1999. Groundwork of the Metaphysics of Morals. In Practical Philosophy. Edited by Mary J. Gregor. Cambridge: Cambridge University Press.

Kauppinen, Antti. 2009. "Working Hard and Kicking Back: The Case for Diachronic Perfectionism." Journal of Ethics and Social Philosophy 3 (April): 1-10.

Koehn, Daryl. 1998. "Virtue Ethics, the Firm, and Moral Psychology." Business Ethics Quarterly 8 (3): 497-513.

Kraut, Richard. 2007. What Is Good and Why: The Ethics of Well-Being. Cambridge, MA: Harvard University Press.

Loacker, Bernadette, and Sara Louise Muhr. 2009. "How Can I Become a Responsible Subject? Towards a Practice-Based Ethics of Responsiveness." Journal of Business Ethics 90 (2): 265-77.

MacIntyre, Alasdair. 2007. After Virtue: A Study in Moral Theory. 3rd ed. Notre Dame: University of Notre Dame Press.

McCracken, Janet, and Bill Shaw. 1995. "Virtue Ethics and Contractarianism: Towards a Reconciliation." Business Ethics Quarterly 5 (2): 297-312.

Mele, Domenec. 2001. “Loyalty in Business: Subversive Doctrine or Real Need?" Business Ethics Quarterly 11 (1): 11-26.

Michaelson, Christopher, Michael G. Pratt, and Adam M. Grant. 2014. "Meaningful Work: Connecting Business Ethics and Organization Studies.” Journal of Business Ethics 121 (1): 77-90.

Mill, John Stuart. 2017. Utilitarianism: With Related Remarks from Mill's Other Writings. Edited by Ben Eggleston. Indianapolis: Hackett.

Moberg, Dennis J., and Mark A. Seabright. 2000. “The Development of Moral Imagination.” Business Ethics Quarterly 10 (4): 845-84.

Moore, Geoff. 2005a. "Humanizing Business: A Modern Business Ethics Approach." Business Ethics Quarterly 15 (2): 237-55.

Moore, Geoff. 2005b. "Management as a Domain-Relative Practice that Requires and Develops Practical Wisdom.” Business Ethics Quarterly 15 (4): 659-85.

Moore, Geoff. 2008. "Re-Imagining the Morality of Management: A Modern Virtue Ethics Approach.” Business Ethics Quarterly 18 (4): 483-511.

Norris, Andrew. 2017. Becoming Who We Are: Politics and Practical Philosophy in the Work of Stanley Cavell. Oxford, New York: Oxford University Press.

Oates, Joyce Carol. 1985. Solstice. New York: Dutton.

Plato. 1997. “Apology.” In Plato: Complete Works. Edited by John M. Cooper. Indianapolis, Cambridge: Hackett.

Rawls, John. 1999. A Theory of Justice. 2nd ed. Cambridge, MA: Belknap Press.

Roche, Bruno, Jay Jakub, Colin Mayer, and Martin Radvan. 2017. Completing Capitalism: Heal Business to Heal the World. 1st ed. Oakland: Berrett-Koehler Publishers.

Savitz, Andrew. 2013. The Triple Bottom Line: How Today's Best-Run Companies Are Achieving Economic, Social and Environmental Success-and How You Can Too. 2nd ed. San Francisco, CA: Jossey-Bass.

Seglow, Jonathan, and Ruth Yeoman. 2010. "Work, Recognition and the Market." Renewal: A Journal of Labour Politics 18 (1/2): 7-12.

Sekerka, Leslie E., Debra R. Comer, and Lindsey N. Godwin. 2014. "Positive Organizational Ethics: Cultivating and Sustaining Moral Performance." Journal of Business Ethics 119 (4): 435-44. 
Seligman, Martin. 2012. Flourish: A Visionary New Understanding of Happiness and WellBeing. New York: Free Press.

Solomon, Robert C. 1992. "Corporate Roles, Personal Virtues: An Aristotelean Approach to Business Ethics." Business Ethics Quarterly 2 (3): 317-39.

Solomon, Robert C. 1993. Ethics and Excellence: Cooperation and Integrity in Business. New York: Oxford University Press.

Solomon, Robert C. 1999. "And Now for Something Completely Different: From Heidegger to Entrepreneurship.” Business Ethics Quarterly 9 (1): 169-77.

Solomon, Robert C. 2003. "Victims of Circumstances? A Defense of Virtue Ethics in Business." Business Ethics Quarterly 13 (1): 43-62.

Thomas, Kenneth. 2009. "The Four Intrinsic Rewards That Drive Employee Engagement." Ivey Business Journal (November/December).

Thoreau, Henry. 2006. Walden. Edited by Jeffrey S. Cramer. New Haven, London: Yale University Press.

Turkle, Sherry. 2017. Alone Together: Why We Expect More from Technology and Less from Each Other, revised and expanded ed New York: Basic Books.

Twenge, Jean M. 2006. Generation Me: Why Today's Young Americans Are More Confident, Assertive, Entitled-and More Miserable than Ever Before. Revised and Updated ed. New York: Atria Books.

Vogt, Christopher P. 2005. "Maximizing Human Potential: Capabilities Theory and the Professional Work Environment." Journal of Business Ethics 58 (1-3): 111-23.

Wall, Steven. 2017. "Perfectionism in Moral and Political Philosophy." In Stanford Encyclopedia of Philosophy. Edited by Edward Zalta. Stanford: Metaphysics Research Laboratory.

Walls, Laura. 2017. Henry David Thoreau: A Life. Chicago, London: University of Chicago Press.

Walton, Clarence C. 1993. "Business Ethics and Postmodernism: A Dangerous Dalliance." Business Ethics Quarterly 3 (3): 285-305.

Watkins, Alison, and Ronald Paul Hill. 2007. "A Simulation of Moral Behavior within Marketing Exchange Relationships." Journal of the Academy of Marketing Science 35 (September): 417-29.

Weaver, Gary R. 2006. "Virtue in Organizations: Moral Identity as a Foundation for Moral Agency." Organization Studies 27 (3): 341-68.

Werhane, Patricia H. 1998. "Moral Imagination and the Search for Ethical DecisionMaking in Management." Business Ethics Quarterly (The Ruffin Series \#1): 75-98.

Werhane, Patricia H. 1999. Moral Imagination and Management Decision-Making. Oxford, New York: Oxford University Press.

Werhane, Patricia H. 2002. "Moral Imagination and Systems Thinking." Journal of Business Ethics 38 (1/2): 33-42.

Werhane, Patricia H. 2006. "A Place for Philosophers in Applied Ethics and the Role of Moral Reasoning in Moral Imagination: A Response to Richard Rorty." Business Ethics Quarterly 16 (3): 401-8.

Weymes, Ed. 2005. "Organizations Which Make a Difference: A Philosophical Argument for the 'People Focused Organization." Corporate Governance 5 (2): 142-58.

Wittgenstein, Ludwig. 2009. Philosophical Investigations. Edited by P. M. S. Hacker and Joachim Schulte. Translated by G. E. M. Anscombe, P. M. S. Hacker, and Joachim Schulte. Malden, Oxford: Wiley-Blackwell.

Yeoman, Ruth. 2014. "Conceptualizing Meaningful Work as a Fundamental Human Need." Journal of Business Ethics 125 (1): 235-51. 